\title{
Effect of rhizosphere microorganisms on the adaptation of regenerated plants of apple clonal rootstocks to ex vitro conditions
}

\author{
Veronika Bobkova*1, Tatiana Anokhina ${ }^{2}$, Igor Bjadovskiy ${ }^{1}$, and Sergey Konovalov ${ }^{1}$ \\ ${ }^{1}$ Federal Horticultural Research Center for Breeding, Agrotechnology and Nursery, 4 str. \\ Zagorievskaja, Moscow, 115598, Russia \\ ${ }^{2}$ G.K. Skryabin Institute of Biochemistry and Physiology of Microorganisms, Pushchino Scientific \\ Center for Biological Research of the Russian Academy of Sciences, 5 prosp. Nauki, Pushchino, \\ 142290, Russia
}

\begin{abstract}
In a vegetation experiment, the effect of bacterial preparations Extrasol, Fitosporin-M based on bacterial strains Bacillus subtilis and bacteria strains of the genus Pseudomonas - P. chlororaphis OV17, P. protegens 38a, $P$. putida $\mathrm{O} 9-10$ on the number of rhizosphere microorganisms, growth and development of regenerant plants of apple clone rootstocks in ex vitro conditions was studied. After 90 days of growing plants, the greatest number was found in the $P$. protegens 38 a strain -0.56 million CFU/g roots. Artificial inoculation of the roots of regenerant plants contributed to a significant increase in the total number of native microorganisms as compared to the control. The most diverse bacterial population in terms of cultural and morphological characteristics was revealed in the variant with the treatment of plants with the $P$. putida O9-10 strain. The introduced bacterial strains contributed to an increase in the adaptive capacity and had a phytostimulating effect on the development of plants. The plant survival rate in the process of adaptation to ex vitro conditions is most influenced by the P. putida 09-10 strain compared to the control. The bacterial preparation Fitosporin-M contributes to the improvement of biometric parameters of plant growth.
\end{abstract}

\section{Introduction}

The weak adaptive ability of regenerant plants to ex vitro conditions is a consequence of the heterotrophic type of nutrition of microplants in culture in vitro, low photosynthetic ability of plants, their dehydration due to weak activity of the stomatal apparatus due to prolonged exposure to cytokinins, the absence of second-order roots and root hairs in plants [1-4]. Controlling the cultivation parameters before and during the acclimatization period allows for the gradual adaptation of plants to external environmental factors. Pre-acclimatization of M9 apple rootstocks propagated in vitro promoted lower transpiration losses and led to higher plant survival after transplantation [4]. Cultivation of microplants in aseptic in vitro conditions, and the resulting weak colonization of root systems by associative microflora

* Corresponding author: vstisp.agrochem @yandex.ru 
contributes to additional stress of regenerated plants caused by the impact of aboriginal microflora of non-sterile substrates during post-vitro adaptation. Various endophytic microorganisms are associated in plant tissues under in vitro conditions, performing both a positive effect and capable of limiting their growth and development [6-8]. Their role in the settlement of the rhizosphere and their importance in the further development of regenerant plants under ex vitro conditions have not been studied at present. High efficiency was demonstrated by artificial inoculation of the root systems of regenerant plants in order to adapt them to ex vitro conditions by various associative microorganisms based on arbuscularvesicular fungi, ascomycete fungi of the genus Trichoderma, bacteria of the genera Bacillus, Azospirillum, Pseudomonas, etc. [4, 5, 9-15]. At present, microbiological preparations based on $B$. subtilis Extrasol, Fitosporin-M have been developed and are used in biologized agricultural technologies for the cultivation of agricultural plants [16]. The strains of rhizosphere bacteria of the genus Pseudomonas, promising for the creation of biological products intended to protect and stimulate plant growth, which combine phytostimulating properties, resistance to heavy metals, and have the ability to biodegrade organic pollutants, have been obtained [14,15]. The positive effect of bacteria of the genus Pseudomonas on plants is to stimulate plant growth through the synthesis of phytohormones, improve mineral nutrition, and suppress the development of phytopathogenic fungi and bacteria [14].

Purpose of the work: to study the effect of inoculation of roots of regenerated plants of clonal rootstocks of apple trees 57-545 with bacteria $B$. subtilis Ch-13 (biological product Extrasol), B. subtilis 26 D (biological product Fitosporin-M), P. chlororaphis OV17, $P$. protegens $38 \mathrm{a}, P$. putida $\mathrm{O} 9-10$ on the total number of rhizosphere microorganisms, plant growth and development in ex-vitro conditions.

\section{Materials and methods}

\subsection{Conditions of plant growing}

The studies were carried out in 2020-2021 in a vegetation experiment with plants-regenerants of apple rootstocks $57-545$ after in vitro culture, in containers with a capacity of $0.5 \mathrm{~kg}$ of soil. A 3:1 peat-sand mixture was used as a nutrient substrate. The content of nutrients in the substrate before setting the experiment, $\mathrm{mg} / \mathrm{kg}$ : alkaline hydrolysable $\mathrm{N}-5.68 \mathrm{mg} / 100 \mathrm{~g}$, mobile $\mathrm{P}_{2} \mathrm{O}_{5}-6.65 \mathrm{mg} / 100 \mathrm{~g}$, mobile $\mathrm{K}_{2} \mathrm{O}-11.53 \mathrm{mg} / 100 \mathrm{~g}, \mathrm{pH}_{\mathrm{KCl}}-6,7$, $\mathrm{pH}$ of the aqueous extract - 6.8, $\mathrm{N}_{-\mathrm{NH}}-2.2 \mathrm{mg} / 100 \mathrm{~g}, \mathrm{~N}-\mathrm{NO}_{3}-5.3 \mathrm{mg} / 100 \mathrm{~g}, \mathrm{CaO}-12.8 \mathrm{mg} / 100 \mathrm{~g}, \mathrm{MgO}-$ $6.0 \mathrm{mg} / 100 \mathrm{~g}$. Before planting, the roots of apple rootstock plants were kept for 3 hours in aqueous suspensions of microorganisms with a cell concentration of $107 \mathrm{CFU} / \mathrm{ml}$. In each variant, 25 plants were used. The results were processed by the statistical method of analysis of variance using the MS Excel software package (v. 2016).

\subsection{Bacterial strains}

We used bacteria of the genera Bacillus and Pseudomonas, which have multiple positive effects on plant development. For the inoculation of plants with B. subtilis strains, the drugs Extrasol and Fitosporin-M were used, which are widely represented on the Russian market. The B. subtilis Ch-13 strain is active bioagent of the Extrasol drug. The biopreparation formulation is liquid, the cell and spore titer is not less than 100 million CFU/ml. The active ingredient of the biological product Fitosporin-M is B. subtilis strain $26 \mathrm{D}$. The biopreparation formulation is liquid, the titer of living cells and spores is not less than 1 billion CFU $/ \mathrm{ml}$. These biological products are designed to improve nutrition, accelerate plant growth and development, as well as to increase resistance to fungal and bacterial infections. 
For inoculation of plants with rhizosphere strains of pseudomonads, we used pure cultures of bacteria with a number of at least 1 billion $\mathrm{CFU} / \mathrm{ml}$ obtained by batch cultivation. Strains P. chlororaphis OV17 (BKM B-2391D), P. protegens 38a (BKM B-3228D), P. putida O910 (VKM B-2955D) synthesize antibiotic active compounds (phenazines - strain OV17, O910 , pyoluteorin - strain 38a), hydrogen cyanide, auxins, surfactants, solubilize phosphates $(\mathrm{O} 9-10,38 \mathrm{a})$, inhibit the growth of phytopathogenic fungi Rhizoctonia solani, Gaeumannomyces graminis var. tritici, Fusarium graminearum and Pectobacterium wasabiae bacteria. The $P$. chlororaphis OV17 strain contains the naphthalene biodegradation plasmid, which provides it with the ability to utilize naphthalene and salicylate as the only source of carbon and energy [14].

\subsection{Cultivation conditions}

The media below were used to grow the bacteria. Medium LB (Maniatis et al., 1984), containing in $\mathrm{g} / \mathrm{L}$ : bacto-tryptone - 10.0, yeast extract - 5.0, $\mathrm{NaCl}-10.0$. King $\mathrm{B}$ medium (for isolation and differentiation of fluorescent bacteria), g/l: bacto-peptone - 20, glycerol $10, \mathrm{~K}_{2} \mathrm{HPO}_{4}-1.5, \mathrm{MgSO}_{4} \times 7 \mathrm{H}_{2} \mathrm{O}$ - 1.5. Pseudomonas Isolation Medium (PIA) (Pseudomonasisolationagar, Sigma, USA). The synthetic medium was M9 (Maniatis et al., 1984) containing in $\mathrm{g}, \mathrm{ml} / \mathrm{L}$ : $\mathrm{Na}_{2} \mathrm{HPO}_{4}-6, \mathrm{KH}_{2} \mathrm{PO}_{4}-3, \mathrm{NaCl}-0.5, \mathrm{NH}_{4} \mathrm{Cl}-1,1 \mathrm{M} \mathrm{MgSO} 4-$ $2,1 \mathrm{M} \mathrm{CaCl}_{2}-1, \mathrm{pH} 7.5$. The last two solutions were sterilized separately and added to the prepared medium. To obtain agar media, $15 \mathrm{~g} / \mathrm{L}$ agar agar (Difco, USA) was added.

Growth substrates used for the differentiation of pseudomonads - xylose, trehalose, mesoinositol, adipic, benzoic, phenylacetic, salicylic, anthranilic, hippuric acids - were added to M9 medium to a final concentration of $0.5 \mathrm{~g} / \mathrm{L}$. Water-insoluble aromatic acids were introduced into the growth medium in the form of sodium salts. Bacteria were grown at $30^{\circ}$ $\mathrm{C}$ on agar media in Petri dishes or in liquid medium on a shaker $(150 \mathrm{rpm})$ in Erlenmeyer flasks containing 200-250 $\mathrm{ml}$ of nutrient medium.

For carrying out vegetation experiments, strains of bacteria of the genus Pseudomonas were grown in LB medium diluted 2 times until the late logarithmic growth phase. The number of cells of the $P$. chlororaphis OV17 strain was $2 \times 109-3 \times 109 \mathrm{CFU} / \mathrm{ml}, P$. protegens 38a - 5×109 - 6×109 CFU/ml, P. putida O9-10 - 1×109 - 3×109 CFU/ml. For the treatment of plant roots, cultures of strains $107 \mathrm{CFU} / \mathrm{ml}$ were used.

The number of introduced microorganisms in the rhizosphere of apple rootstocks was determined on day 90 . For this purpose, the roots of plants were isolated, successive washings were made from their surface in physiological solution according to Tepper E.Z. (2004) and plated the corresponding dilutions on agar media TSA (trypticase-soy agar), MPA (meatpeptone agar), SAA (starch-ammonia agar), acidified Czapek's medium. Individual colonies were replicated onto King B, PIA, LB, and M9 media containing various carbon and energy sources. The experiment was carried out in triplicate.

\section{Results and discussion}

The $P$. putida 09-10 strain exerted the greatest influence on the survival rate of regenerated plants of apple-tree rootstocks 57-545 in the process of adaptation to ex vitro conditions in comparison with the control (Table 1). The biometric indicators of plant growth were mostly influenced by Fitosporin-M. 
Table 1. Influence of inoculation on biometric indicators of plant development of apple rootstocks

\begin{tabular}{|c|c|c|c|c|}
\hline $\begin{array}{c}\text { Experiment } \\
\text { variant }\end{array}$ & $\begin{array}{c}\text { Plant survival, } \\
\%\end{array}$ & $\begin{array}{c}\text { Plant } \\
\text { height, cm }\end{array}$ & $\begin{array}{c}\text { Main root } \\
\text { length, cm }\end{array}$ & $\begin{array}{c}\text { Number of } \\
\text { leaves, pcs / } \\
\text { plant }\end{array}$ \\
\hline Control & 27 & 6.0 & 2.5 & 20 \\
\hline Extrasol & 28 & 5.0 & 4.7 & 29 \\
\hline Fitosporin-M & 47 & 10.5 & 8.5 & 37 \\
\hline P. putida 09-10 & 57 & 5.7 & 6.7 & 36 \\
\hline P.protegens 38a & 35 & 4.7 & 4.3 & 29 \\
\hline $\begin{array}{c}\text { P. chlororaphis } \\
\text { OV17 }\end{array}$ & 40 & 5.0 & 2.8 & 16 \\
\hline $\begin{array}{c}\text { LSD05 } \\
\text { (least significant } \\
\text { difference 95\%) }\end{array}$ & 0.4 & 0.4 & $*$ Femp $<* *$ Fcrit & $*$ Femp $<*$ Fcrit \\
\hline
\end{tabular}

* empirical value of Fisher's F-test;

** critical value of Fisher's F-test.

Root samples were taken from the rhizosphere of plants treated with microorganisms, 90 days after inoculation, and from the corresponding dilutions were inoculated on agar media TSA, MPA, KAA, Czapek's medium. The total number of microorganisms in the variants with inoculation on all nutrient media was significantly higher compared to the control (table 2).

Table 2. Influence of bacterization on the number of cultivated microorganisms, million CFU/g roots

\begin{tabular}{|c|c|c|c|c|}
\hline \multirow{2}{*}{ Experiment variant } & \multicolumn{4}{|c|}{ Cultivation medium } \\
\cline { 2 - 5 } & TSA & MPA & SAA & $\begin{array}{c}\text { Czapek's } \\
\text { medium }\end{array}$ \\
\hline Control & 0.006 & 0.78 & 0.006 & 0.059 \\
\hline Extrasol & 1.97 & 0.53 & 1.74 & 0.98 \\
\hline Fitosporin-M & 1.18 & 1.31 & 1.64 & 0.99 \\
\hline P. putida $09-10$ & 0.65 & 0.98 & 0.87 & 0.87 \\
\hline P. protegens 38a & 1.14 & 1.13 & 1.25 & 0.84 \\
\hline P. chlororaphis OV17 & 0.76 & 1.23 & 1.06 & 0.51 \\
\hline
\end{tabular}

For the variants of the experiment with the introduction of Pseudomonas strains, individual colonies differing in morphological characteristics were plated on TSA medium and then a pure culture of microorganisms was tested for the ability to grow on King B, PIA, M9 nutrient media containing various organic substrates as the only source of carbon and energy. Strains $P$. chlororaphis OV17, P. protegens 38a, and P. putida O9-10, which were used for plant inoculation, were used as controls.

These strains belong to the fluorescent group of pseudomonads. They produce pyoverdins, water-soluble fluorescent pigments that, when exposed to ultraviolet radiation, give bacterial colonies their characteristic blue-green color. In addition, the $P$. chlororaphis OV17 strain is characterized by bright orange colonies, which is associated with the production of phenazine-1-carboxylic acid hydroxy derivatives. The strains differ from each other in their ability to utilize some organic carbon sources - adipic, phenylacetic and salicylic acids. $P$. putida O9-10 does not grow on these compounds, $P$. protegens 38 a utilizes adipate and phenyl acetate, and $P$. chlororaphis OV17 is capable of growing only on salicylate.

Several morphotypes of colonies were revealed on a complete TSA medium in each variant of treatment with rhizosphere strains. The most phenotypically diverse bacterial 
population was found in variants with plant inoculation with $P$. putida O9-10 and $P$. protegens 38a strains - 7 and 6 morphotypes, respectively. Treatment of plants with the $P$. chlororaphis OV17 strain revealed two types of colonies. All selected isolates differed from the control strains in terms of cultural and morphological characteristics. Most of them, except for isolate 471-1, were able to grow on King B and PIA media, but did not produce green fluorescent pigment. The only exception was the strain 471-3, which completely corresponded to the $P$. protegens 38 a strain in terms of the morphology and coloration of colonies, fluorescence on complete nutrient media, and the spectrum of utilized substrates. Its number in the rhizosphere of plants was 0.56 million CFU/g of roots. After 90 days of plant cultivation, it was not possible to detect the strains of $P$. chlororaphis OV17 and $P$. putida O9-10 according to the cultural and morphological characteristics.

\section{Conclusion}

Bacterial drugs Extrasol, Fitosporin-M based on bacterial strains Bacillus subtilis and rhizosphere strains of bacteria of the genus Pseudomonas - P. chlororaphis OV17, P. protegens $38 \mathrm{a}, P$. putida O9-10 have a significant positive effect on the growth and development of regenerated plants under ex vitro during the first 90 days of adaptation. The plant survival rate in the process of adaptation to ex vitro conditions was most influenced by the $P$. putida O9-10 strain compared to the control. The bacterial preparation Fitosporin-M had a greater effect on biometric parameters of plant growth.

Artificial inoculation of the roots of regenerant plants contributed to a significant increase in the number of microorganisms cultivated on elective agar media in comparison with the control. In each variant of treatment with rhizosphere strains, several different colony morphotypes were identified. The most diverse in terms of cultural and morphological characteristics, the bacterial population was found in the variant with inoculation of plants with the P. putida O9-10 strain (7 morphotypes). All selected strains, with the exception of 471-1, were able to grow on King B and PIA media, but did not produce green fluorescent pigment. Isolate 471-3 corresponded to $P$. protegens strain $38 \mathrm{a}$ in terms of colony morphology and coloration, fluorescence on full-fledged nutrient media, and the spectrum of utilized substrates.

After 90 days of growing plants of apple rootstocks, the number of introduced strains of pseudomonads significantly decreased. We failed to isolate the $P$. chlororaphis OV17 and $P$. putida 09-10 strains by cultural and morphological characters, and the number of $P$. protegens $38 \mathrm{a}$ was 0.56 million CFU/g roots. Nevertheless, over 90 days of cultivation, the strains contributed to an increase in the adaptive capacity and had a phytostimulating effect on plant development.

\section{References}

1. J. A. Teixeira da Silva, A. Gulyás, K. Magyar-Tábori, M.R. Wang, Q.C. Wang, J. Dobránszki., Planta, 249, 975-1006 (2019) https://doi.org/10.1007/s00425-019-03100-X

2. J. Dobránszki, N. M. Drienyovszki, J. Plant Physiol., 171(16), 1472-1478 (2014) https://doi.org/10.1016/j.jplph.2014.06.015

3. S.M. Ko, J.H. Lee, M.M. Oh, Hort. Envi. Biotechnol. 59(3), 303-313 (2017) http://doi.org/10.1007/s13580-018-0038-7

4. R. Mahendra, N. Chauhan, J. B. Sharma, K. Rana, M. Bakshi, Int. J. Curr. Microbiol. App. Sci., 9(11), 3321-3329 (2020) https://doi.org/10.20546/ijcmas.2020.911.397 
5. D. M. Zeffa, L.J. Perini, M.B. Silva, N.V. de Sousa, C.A. Scapim, A.L.M. de Oliveira, A.T. do Amaral Jr., L.S.A. Gonçalves, PLoS ONE, 14(4), e0215332 (2019) https://doi.org/10.1371/journal.pone.0215332

6. S.E. Dunaeva, Yu.S. Osledkin, Agricult. Biol., 50(1), 3-15 (2015) http://dx.doi.org/10.15389/agrobiology.2015.1.3eng

7. L. S. Samarina, V.I. Malyarovskaya, E.V. Rogozhina, L.S. Malyukova, Agricult. Biol., 52(5), 917-927 (2017) http://doi.org/10.15389/agrobiology.2017.5.917eng

8. A. Soumare, A.G. Diédhiou, N.K. Arora, L.K.T. Al-Ani, M. Ngom, S. Fall, M. Hafidi, Y. Ouhdouch, L. Kouisni, M.O. Sy, Front. Microbiol., 12, 649878 (2021) https://doi.org/10.3389/fmicb.2021.649878

9. Y. Rouphael, P. Franken, C. Schneider, D. Schwarz, M. Giovannetti, M. Agnolucci, S. De Pascale, P. Bonini, G. Colla, Sci. Hortic. 196, 91-108 (2015) http://doi.org/10.1016/j.scienta.2015.09.002

10. Q. S. Wu, Y. N. Zou, G. Y. Wang, J. Comm. Soil Sc. Plant Anal., 42(15), 1825-1832 (2011) https://doi.org/10.1080/00103624.2011.587570

11.Y. Rouphael, G. Colla, Front. Plant Sci. 11, $40 \quad$ (2020) http://doi.org/10.3389/fpls.2020.00040

12. J. López-Bucio, R. Pelagio-Flores, A. Herrera-Estrella, Sci. Hortic. 196, 109-123 (2015) https://doi.org/10.1016/j.scienta.2015.08.043

13. Y.C. Kim, A.J. Anderson, Mol. Plant Pathol., 19(10), 2349-2359 (2018) https://doi.org/10.1111/mpp.12693

14. T.V. Siunova, T.O. Anokhina, O.I. Sizova, S.L. Sokolov, O.I. Sazonova, V.V. Kochetkov, A.M. Boronin, S.G. Patil, A.B. Chudhari, Biotechnol., 2, 56-67 (2017) https://doi.org/10.21519/0234-2758-2017-33-2-56-67

15. T.Z. Esikova, T.O. Anokhina, T.N. Abashina, N.E. Suzina, I.P. Solyanikova, Microorganisms, 9, 755 (2021). https://doi.org/10.3390/microorganisms9040755

16. R. Aipova, A.B. Abdykadyrova, A.A. Kurmanbayev, Plant Biotechnol. Breed., 2(4), 3641 (2019) https://doi.org/10.30901/2658-6266-2019-4-o4 